Ciência Florestal, Santa Maria, v. 22, n. 3, p. 631-641, jul.-set., 2012

ISSN 0103-9954

\title{
FENOLOGIA, MORFOLOGIA E ANÁLISE DE SEMENTES DE Cordia trichotoma (Vell.) Arráb. ex Steud.
}

\author{
PHENOLOGY, MORPHOLOGY AND ANALYSIS OF SEEDS OF \\ Cordia trichotoma (Vell.) Arráb. ex Steud.
}

\author{
Marciele Felippi ${ }^{1}$ Charles Rodrigo Belmonte Maffra ${ }^{2}$ Edison Bisognin Cantarelli ${ }^{3}$ \\ Maristela Machado Araújo ${ }^{4}$ Solon Jonas Longhi ${ }^{5}$
}

\begin{abstract}
RESUMO
No presente trabalho se estudou a fenologia e morfologia, como também foram realizados testes físicos e fisiológicos com sementes de Cordia trichotoma (Vell.) Arráb. ex Steud (louro-pardo). A coleta do material botânico e as observações fenológicas foram realizadas em cinco árvores matrizes, localizadas no Município de Frederico Westphalen, Rio Grande do Sul, de março de 2007 a março de 2010. O trabalho foi conduzido em condições de laboratório e viveiro, na Universidade Federal de Santa Maria, Rio Grande do Sul. Durante os três anos, a floração teve maior intensidade de março a abril e a frutificação, de maio a junho. A espécie possui inflorescência cimosa, paniculada, constituída de pequenas flores de coloração branca, hermafroditas. O fruto é simples, drupáceo, encerrado pelo tubo da corola e pelo cálice persistente. A semente, de formato cilíndrico, elipsoidal, de coloração castanha, exalbuminosa, com embrião cotiledonar, basal, invaginado e cotilédones plicados, presos em torno do eixo hipocótilo radicular. A germinação é epígea e a plântula fanerocotiledonar. As sementes são recalcitrantes e o número médio por quilograma foi de 24.591, a umidade das sementes $51 \%$, a germinação $40 \%$ e a emergência $29 \%$. O índice germinativo é oscilante comparando os resultados deste trabalho a outros, provavelmente devido à qualidade das sementes, variável em função de cada árvore matriz e seu micro-habitat. Portanto, há importância em selecionar indivíduos, observando características que trarão representação genética e fisiológica da espécie, aumentando, assim, a homogeneidade do lote de sementes.
\end{abstract}

Palavras-chave: louro-pardo; germinação; plântula; muda.

\section{ABSTRACT}

On this paper, the phenology and morphology as well as physical and physiological tests were carried out with seeds of Cordia trichotoma (Vell.) Arráb. ex Steud. The collection of botanical material and phenological observations were performed on five selected trees located in Frederico Westphalen, Rio Grande do Sul state, from March 2007 to March 2010. The work was conducted under laboratory and greenhouse conditions at the Universidade Federal de Santa Maria, Rio Grande do Sul state. For three years, the bloom was most intense from March to April and the fruiting from May to June. The species has inflorescence, paniculate, consisting of small white colored and hermaphrodite flowers. The fruit is simple,

1. Bióloga, Dra, Professora Colaboradora do Departamento de Ciências Biológicas, Universidade Estadual do Centro-Oeste, Rua Camargo Varela de Sá, Vila Carli, CEP 85040-080, Guarapuava (PR).marciele.f@bol.com.br

2. Graduando em Engenharia Florestal, Universidade Federal de Santa Maria, Centro de Educação Superior Norte do Rio Grande do Sul, Universidade Federal de Santa Maria, Linha 7 de Setembro, BR 386, Km 40, CEP 98400-000, Frederico Westphalen (RS). charles.mafra@hotmail.com

3. Engenheiro Florestal, Dr., Professor Adjunto do Departamento de Engenharia Florestal, Universidade Federal de Santa Maria, Centro de Educação Superior Norte do Rio Grande do Sul, Linha 7 de Setembro, BR 386, Km 40, CEP 98400-000, Frederico Westphalen (RS). engedison@yahoo.com.

4. Engenheira Florestal, Dra, Professora Adjunta do Departamento de Engenharia Florestal, Centro de Ciências Rurais, Universidade Federal de Santa Maria, Av. Roraima, 1000, CEP 97105-900, Santa Maria (RS). araujo.maristela@gmail.com

5. Engenheiro Florestal, Professor Titular do Departamento de Engenharia Florestal, Centro de Ciências Rurais, Universidade Federal de Santa Maria, Av. Roraima, 1000, CEP 97105-900, Santa Maria (RS). longhi.solon@gmail.com

Recebido para publicação em 18/07/2010 e aceito em 06/05/2011 
drupaceous, terminated by the corolla tube and by the persistent calyx. The seed is cylindrical, ellipsoidal, pale brown exalbuminous, cotyledonary embryo with baseline, and invaginated plicate cotyledons, trapped around the root hypocotyl axis. The germination is epigeal and the seedling phanerocotyledonal. Seeds are recalcitrant and the average number was 24,591 per kilogram, the seed moisture content was $51 \%$, the germination was $40 \%$ and the emergence was $29 \%$. The germination index is oscillating comparing the results of this paper to others, probably due to seed quality, which varies according to each parent tree and its micro-habitat. Therefore, there is importance in the selection of individuals, noticing the features that will bring genetic and physiological representation of the species, thus increasing the homogeneity of the seed lot.

Keywords: louro-pardo; germination; seedling.

\section{INTRODUÇÃO}

Louro-pardo (Cordia trichotoma (Vell.) Arráb. ex Steud.) - Boraginaceae, é uma espécie arbórea medindo 25 a 35 metros de altura e de 5 a $100 \mathrm{~cm}$ de diâmetro (REITZ et al., 1988), seu tronco é reto e cilíndrico, com fuste de 10 a 15 metros (REITZ, 1988; CARVALHO, 2003). A madeira é leve a moderadamente densa $(0,43$ a 0,78 $\mathrm{g} / \mathrm{cm}^{3}$ ), de fácil trabalhabilidade, sendo amplamente empregada para as mais variadas finalidades (REITZ et al., 1988; CARVALHO, 2003).

A produção de mudas de alta qualidade, seja com o propósito econômico ou conservacionista, necessita de conhecimentos morfológicos e silviculturais de cada espécie florestal.

A morfologia possui papel fundamental na compreensão do crescimento, podendo atuar como ferramenta de auxílio na interpretação de testes de germinação (MOURÃO et al., 2002), além da identificação a campo (BOTELHO et al., 2000). Já a fenologia, prevê a época de reprodução da espécie, o comportamento de polinizadores (NEWSTROM et al., 1994), como também é indicadora das condições climáticas e edáficas de um ambiente (FOURNIER, 1967).

Os estudos relacionados à análise de sementes também têm merecido atenção no meio científico, visando à obtenção de informações que permitam avaliar a qualidade fisiológica das sementes.

Nesse sentido, o presente trabalho teve como objetivo a caracterização da época de floração e frutificação, descrição e ilustração morfológica da flor, fruto, semente do louro-pardo, bem como a germinação, plântula e muda, além da quantificação do número de sementes por quilograma, teor de água, e emergência destas.

\section{MATERIAL E MÉTODO}

A coleta de material botânico e as observações fenológicas foram realizadas durante o período de março de 2007 a março de 2010, no Município de Frederico Westphalen $\left(27^{\circ} 24^{\prime} 01,67^{\prime \prime} \mathrm{S} ; 5^{\circ} 25^{\prime} 51,75^{\prime}\right.$ ' W), Rio Grande do Sul (RS).

A cobertura florestal da região pertence ao domínio da Floresta Estacional Decidual e se encontra a $566 \mathrm{~m}$ de altitude, com classificação climática, segundo Köppen, do tipo Cfa, precipitação média anual entre 1.800 e $2.100 \mathrm{~mm}$ e temperatura média anual em torno de $18^{\circ} \mathrm{C}$ (SEMA, 2001).

As análises morfológicas e os testes com sementes foram realizados no Laboratório de Sementes do Departamento de Ciências Florestais na Universidade Federal de Santa Maria (UFSM). As demais foram realizadas no viveiro da UFSM campus Frederico Westphalen (CESNORS), sendo que, os dados climáticos referentes ao período de estudo (Figura 1), também foram obtidos na Estação Meteorológica da UFSM campus Frederico Westphalen. No entanto, os índices pluviométricos foram observados a partir de 2008.

\section{Aspectos fenológicos e coleta de material botânico}

$\mathrm{Na}$ área de estudo, foram selecionadas 20 árvores matrizes, aparentemente sadias, com copa bem distribuída e fuste reto, com distância mínima de $100 \mathrm{~m}$ entre si, de acordo com PiñaRodrigues (2002),

As árvores foram monitoradas mensalmente, observando a presença de flores e frutos, seguindo o método qualitativo utilizado por Fournier (1974). A floração foi classificada como o período em que as árvores possuíam flores em antese e a frutificação quando os frutos estavam maduros (MORELLATO et al., 1989). 
Após a constatação da presença de evento fenológico, intensificaram-se as observações, passando a quinzenais, a fim de analisar os padrões de frequência de indivíduos e ocorrência de cada fenofase, conforme descrito por Newstrom et al. (1994), informações que foram comparadas às condições climáticas.

No decorrer das observações fenológicas, foram coletados, aleatoriamente, na copa de cada árvore matriz, 50 flores e 10 frutos inteiros e sadios, sendo acondicionados em frascos contendo álcool (70 \%) para posterior análise, descrição e ilustração morfológica.

Após a mudança de coloração, de verde para marrom, a coleta foi realizada diretamente nas árvores, que dispuseram de frutos maduros no mesmo período (cinco árvores matrizes), no mês de junho de 2008. Utilizaram-se equipamentos como podão, escada de alumínio e cintos de segurança. Após a coleta, retiraram-se as pétalas persistentes e após o beneficiamento, formou-se o lote de sementes.

\section{Aspectos morfológicos}

Para a análise morfológica, foram realizadas observações, secções transversais e longitudinais, medições e ilustrações dos detalhes externos e internos de flores, frutos e sementes e dos detalhes externos do processo germinativo, plântula e muda, tendo auxílio de lupa de mesa do tipo SZ40 - Olympus e paquímetro mecânico (1/50 mm).

A descrição das flores constou de observação do cálice, corola, androceu e gineceu. Para os frutos, observou-se a textura, consistência, pilosidade, brilho e forma do pericarpo e o número de sementes por fruto. Já para as sementes, observaram-se características externas como a cor, consistência, forma, superfície, tamanho e forma da micrópila, rafe, hilo e partes associadas e sua localização. Internamente, observouse a presença, consistência e coloração de endosperma; posição, forma e tamanho do embrião e do eixo embrionário; e textura, cor e forma dos cotilédones.

Foram medidos, tanto dos frutos quanto das sementes, comprimento (a distância entre a base e o ápice do fruto), largura (o lado mais largo) e espessura (o lado mais estreito).

Para o acompanhamento das fases de germinação e plântula as sementes foram semeadas em substrato papel-toalha, organizado em rolos, umedecido comágua destilada, levadas ao germinador, à temperatura de $25^{\circ} \mathrm{C}$, na presença de luz constante, sendo utilizadas duas repetições de 20 sementes cada. A germinação foi descrita desde a emissão da radícula até a expansão dos protófilos, a qual foi considerada como a fase de plântula.

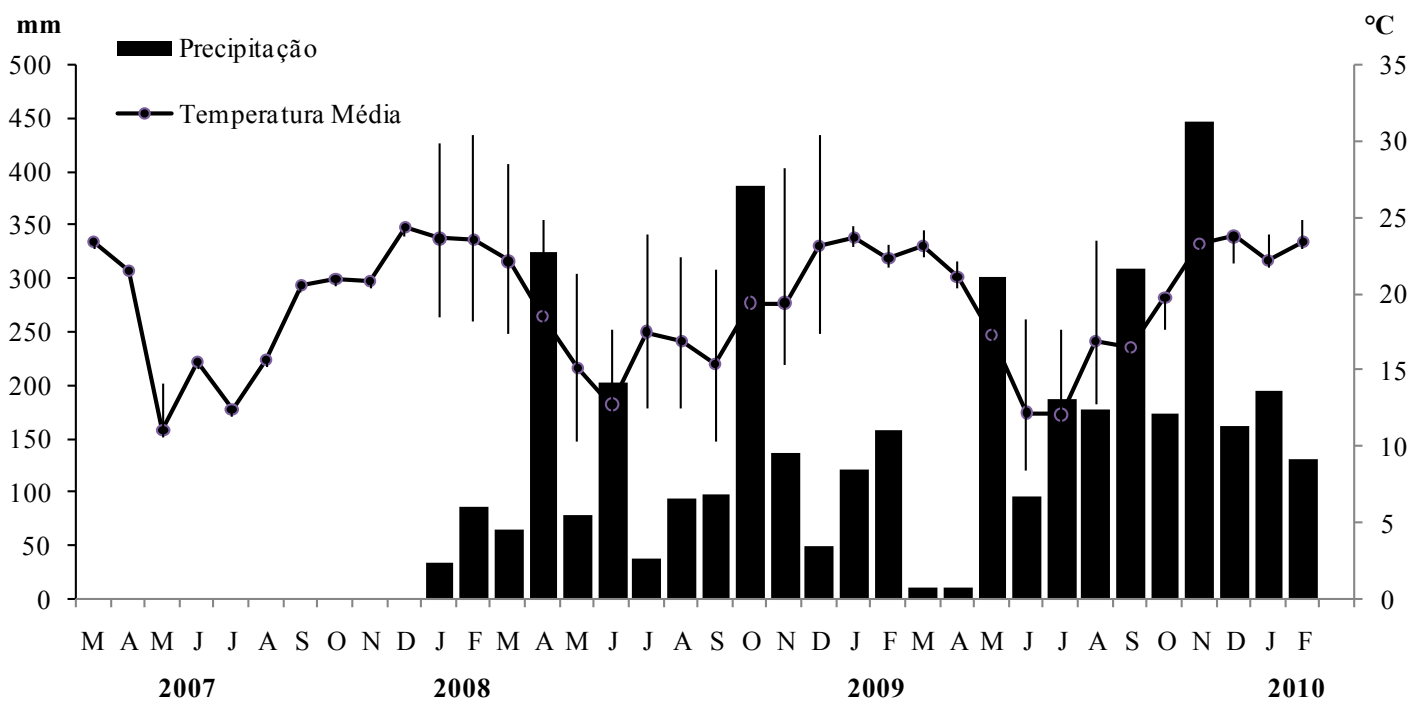

FIGURA 1: Precipitação $(\mathrm{mm})$ e temperatura $\left({ }^{\circ} \mathrm{C}\right)$ : máxima, média e mínima mensal no Município de Frederico Westphalen, RS, no período de observações fenológicas. Fonte: Estação Climatológica da UFSM campus Frederico Westphalen, RS (linhas verticais expressam a temperatura mensal máxima e mínima).

FIGURE 1: Precipitation $(\mathrm{mm})$ and temperature $\left({ }^{\circ} \mathrm{C}\right)$ : maximum and minimum monthly averages in the municipality of Frederico Westphalen, Rio Grande do Sul state, phenological observations. Source: Climatological Station of UFSM, Frederico Westphalen, Rio Grande do Sul state (vertical lines express the maximum and minimum monthly temperature). 
A fim de observar a morfologia da muda, foram utilizados 50 indivíduos produzidos em casa de vegetação por semeadura direta em sacos de polietileno, sendo considerados completamente formados a partir do diâmetro do colo de $3 \mathrm{~mm}$ e altura de $20 \mathrm{~cm}$. Foram utilizados exemplares sadios e bem desenvolvidos para as descrições e ilustrações da raiz, colo, hipocótilo, epicótilo, cotilédones, cicatrizes, protófilo e metáfilo, descrevendo a forma, número, posição, textura, consistência, pilosidade e cor.

A metodologia e a terminologia empregadas para as descrições morfológicas basearam-se nos trabalhos de Agarez et al. (1994), Bell (1991), Gonçalves e Lorenzi (2007) Souza (2003), Vidal e Vidal (2000) e Weberling (1989).

\section{Análises de sementes}

A partir do lote, foram retiradas amostras para determinação do peso de mil sementes e o teor de água, através do método da estufa a $105{ }^{\circ} \mathrm{C} \pm$ $3{ }^{\circ} \mathrm{C}$ por 24 horas, descrito nas Regras de Análises de Sementes (BRASIL, 2009).

O teste germinativo foi conduzido com oito repetições de 25 sementes, em caixa plástica (gerbox) contendo vermiculita média esterilizada, umedecida a $60 \%$ de capacidade de retenção de água. As amostras foram submetidas ao germinador, a $25^{\circ} \mathrm{C} \pm$ $3{ }^{\circ} \mathrm{C}$, com luz branca contínua, sendo o experimento avaliado diariamente, tendo em vista o critério biológico (GUI-FERREIRA e BORGHETTI, 2004) em que as sementes são consideradas germinadas, a partir da emissão de radícula com, no mínimo, $2 \mathrm{~mm}$.

$\mathrm{O}$ teste de emergência foi realizado em casa de vegetação, conduzido em delineamento inteiramente casualizado, utilizando-se 54 tubetes em quatro repetições, totalizando 216 mudas. A semeadura foi realizada em tubetes de $175 \mathrm{~cm}^{3}$, preenchidos com substrato MecPlant Florestal $3^{\circledR}$ à base de casca de pinus, vermiculita e adubação de base, irrigados duas vezes ao dia e avaliados diariamente, onde as sementes foram consideradas emergidas a partir do aparecimento do protófilo, segundo descrição de Gui-Ferreira e Borghetti (2004).

Tanto para o teste germinativo quanto de emergência, foram utilizadas sementes recémcoletadas.

Para os dados de laboratório e viveiro, foram avaliados a Porcentagem de Germinação $(\% \mathrm{G})$ e de Emergência (\%E), o Índice de Velocidade de Germinação (IVG) e de Emergência (IVE), conforme Gui-Ferreira e Borghetti (2004).

\section{RESULTADO E DISCUSSÃO}

\section{Aspectos fenológicos}

Observou-se, ao longo dos três anos, uma floração abundante de fevereiro a junho, com maior intensidade durante os meses de março a abril (Figura 2). As diferenças reveladas pela comparação dos resultados obtidos com outros estudos relativos à mesma espécie, como os de Castiglioni (1975), Rizzini (1976), Reitz et al. (1988) e Carvalho (2003), demonstraram uma provável plasticidade fenotípica, característica relevante e de merecida atenção, reforçando a necessidade de estudos regionais com o intuito de analisar a influência do meio na fenofase.

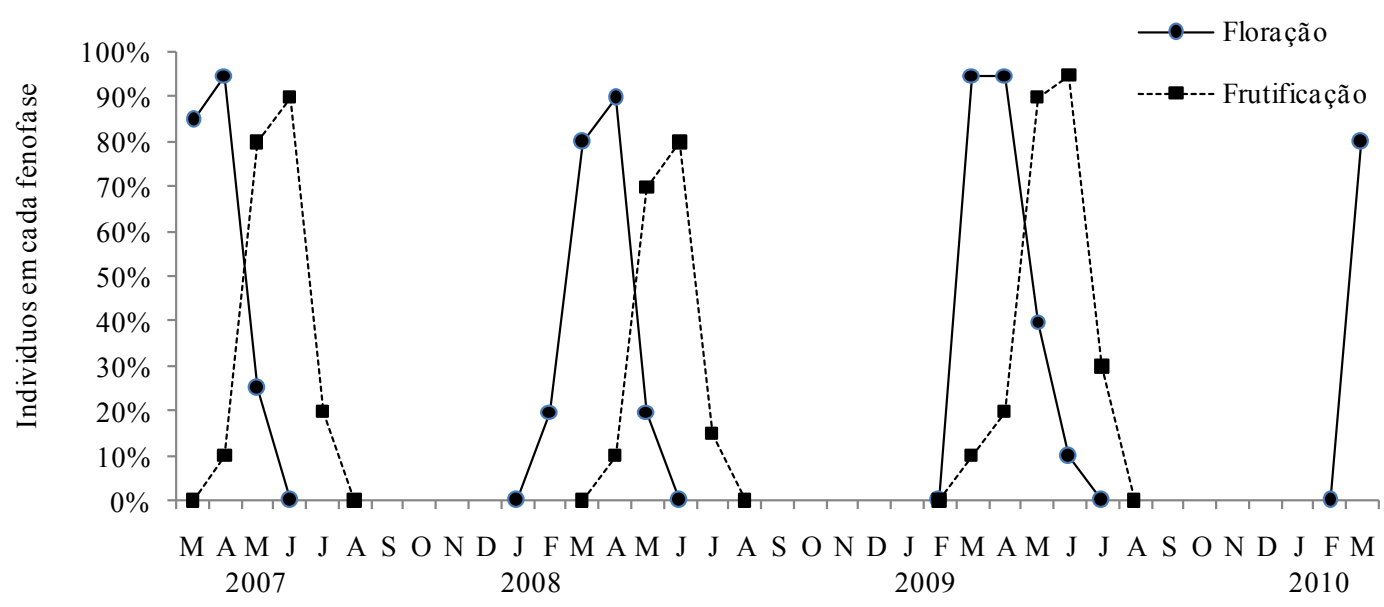

FIGURA 2: Padrão da sazonalidade da floração e frutificação de Cordia trichotoma durante o período de março de 2007 a março de 2010, no Município de Frederico Westphalen, RS.

FIGURE 2: Pattern of seasonality of flowering and fruiting Cordia trichotoma during the period March 2007 to March 2010, in Frederico Westphalen, Rio Grande do Sul state. 
No ano de 2008, durante o período de aparecimento máximo de flores (Figura 2), também foram registradas variações mensais quanto à pluviometria (Figura 1). Houve a queda dos botões florais, sugerindo que o excesso de chuvas durante a floração prejudique o desenvolvimento inicial de frutos.

Em 2009, houve o aparecimento de um número maior de indivíduos floridos, juntamente com maior quantidade de flores, sendo que a pluviometria, durante esta fase, foi baixa (Figura 1), o que pressupõe que a espécie não necessite tanto de umidade para manter suas flores. Tal fato pode estar associado ao pequeno tamanho dos botões florais ou à intensa floração somente a cada dois anos, como descreve Aguiar et al. (1993).

As fenofases tiveram frequência anual. A presença de botões florais e, posteriormente, frutos sugere a ocorrência de floração de curta duração, podendo ser confirmada com o estudo da biologia floral e com o intervalo menor entre observações.

Na sequência, observou-se a maturação dos frutos de março a julho, porém, o amadurecimento predominou de maio a junho (Figura 2), juntamente com os maiores índices pluviométricos (Figura 1). O período de ocorrência da frutificação para o presente trabalho está de acordo com as descrições de Castiglioni (1975). No entanto, observaramse, neste estudo, diferenças fenológicas entre anos consecutivos, não havendo sincronismo para as 20 árvores matrizes inicialmente selecionadas. A irregularidade produtiva entre anos consecutivos e entre matrizes pode estar associada a fatores genéticos e ao micro-habitat.

A espécie pode estar respondendo a estímulos ambientais como fotoperíodo, precipitação e temperatura. De acordo com Spina et al. (2001), fatores bióticos, como polinizadores e dispersores de frutos e sementes, também afetam as fenofases. De qualquer forma, a fenologia auxilia a identificação do período apropriado para a coleta de sementes (PIÑA-RODRIGUES, 2002), sendo de extrema importância observações individuais das árvores matrizes, já que a maturação de frutos pode variar numa mesma população, influenciando os testes físicos e fisiológicos com sementes.

\section{Aspectos morfológicos}

A inflorescência é cimoso-paniculada, terminal, constituída por grupos de pequenas flores de coloração branca (Figura 3 -A), com prefloração valvar simples. A flor é pedunculada, cíclica, diclamídea, heteroclamídea, hermafrodita (Figura 3 - B; C), isostêmone, hipógina, ovário súpero, cálice gamossépalo (Figura 3 - B; D; G) de coloração verde, assimétrico. É gamopétala, pentâmera, actinomorfa, infundibuliforme, possuindo desde sua base 1,5 a $2 \mathrm{~cm}$ de altura e 0,4 a $0,5 \mathrm{~mm}$ de largura.

As descrições relatadas concordam com Reitz et al. (1988) e Souza (2008). No entanto, tratando-se do sistema sexual, discorda de Carvalho (2003), o qual descreve a espécie como polígama e quanto ao ovário, o autor cita o tipo ínfero.

Os estames estão soldados na base das pétalas, homodínamos, com filete simples, antera livre, dorsifixa (Figura 3 - D; E), de coloração amarela, com $\pm 2 \mathrm{~mm}$ de comprimento e $\pm 1 \mathrm{~mm}$ de largura, e filete de $\pm 1 \mathrm{~cm}$ de altura e $\pm 1 \mathrm{~mm}$ de largura.

O gineceu é unicarpelar, terminal, com formato globoso, placentação axial com dois a quatro lóculos e um a quatro óvulos (Figura $3-\mathrm{D}$; F; G), sendo que, somente um se desenvolve em semente, concordando com Taroda e Gibbs (1986). Já o estigma é ramificado em três partes. De acordo com Smith (1970), esta característica dá origem ao nome trichotoma.

Observou-se para a espécie, a presença de heterostilia, característica bem conhecida no gênero Cordia (GIBBS e TARODA, 1983). De acordo com Ganders (1979), a heterostilia é um polimorfismo floral controlado geneticamente, no qual as flores diferem nos comprimentos de estiletes e estames. Encontraram-se estiletes de maior comprimento que os estames, o que pode servir como um mecanismo, reduzindo a autopolinização, ou seja, uma característica que pode influenciar na produção de sementes.

O fruto é simples, drupáceo (Figura $4-\mathrm{A}$ ), o que foi citado por Judd et al. (1999) e Carvalho (2003). O tipo drupáceo também ocorre para Cordia ecalyculata, Cordia sellowiana e Cordia myxa (BARROSO et al., 1999).

De formato subcilíndrico, o fruto é seco, indeiscente, monocárpico, de coloração marrom, totalmente encerrado pelo tubo da corola e pelo cálice persistente, encimado pela base ampliada e estilete persistente (Figura $4-B$ ), concordando com o descrito por Barroso et al. (1999) e Souza (2008).

A semente fica presa à parede do fruto pela base do estigma, dispersando-se a longas distâncias, devido à corola marcescente. Assim, de acordo com Rizzini (1976), as sementes são facilmente reconhecíveis no chão da floresta. 
A semente, de formato cilíndrico, elipsoidal (Figura $4-\mathrm{C}$ ), possui tegumento fino, superfície lisa de coloração castanha, sendo a cicatriz linear basal. Internamente, é exalbuminosa, com embrião cotiledonar, basal, invaginado, cotilédones plicados de coloração branca, presos em torno do eixo hipocótilo-radicular, curto e espesso (Figura 4 C). A informação quanto ao tamanho e localização do embrião se torna útil em testes laboratoriais, como o de tetrazólio, auxiliando cortes e manuseio da semente.

As dimensões de frutos e sementes tiveram ampla variação, sendo que os frutos variaram de 0,9 a $1 \mathrm{~cm}$ de comprimento, 0,4 a $0,5 \mathrm{~cm}$ de largura e 0,4 a $0,45 \mathrm{~cm}$ de espessura, enquanto que nas sementes as dimensões foram de 0,8 a $0,9 \mathrm{~cm}, 0,4$

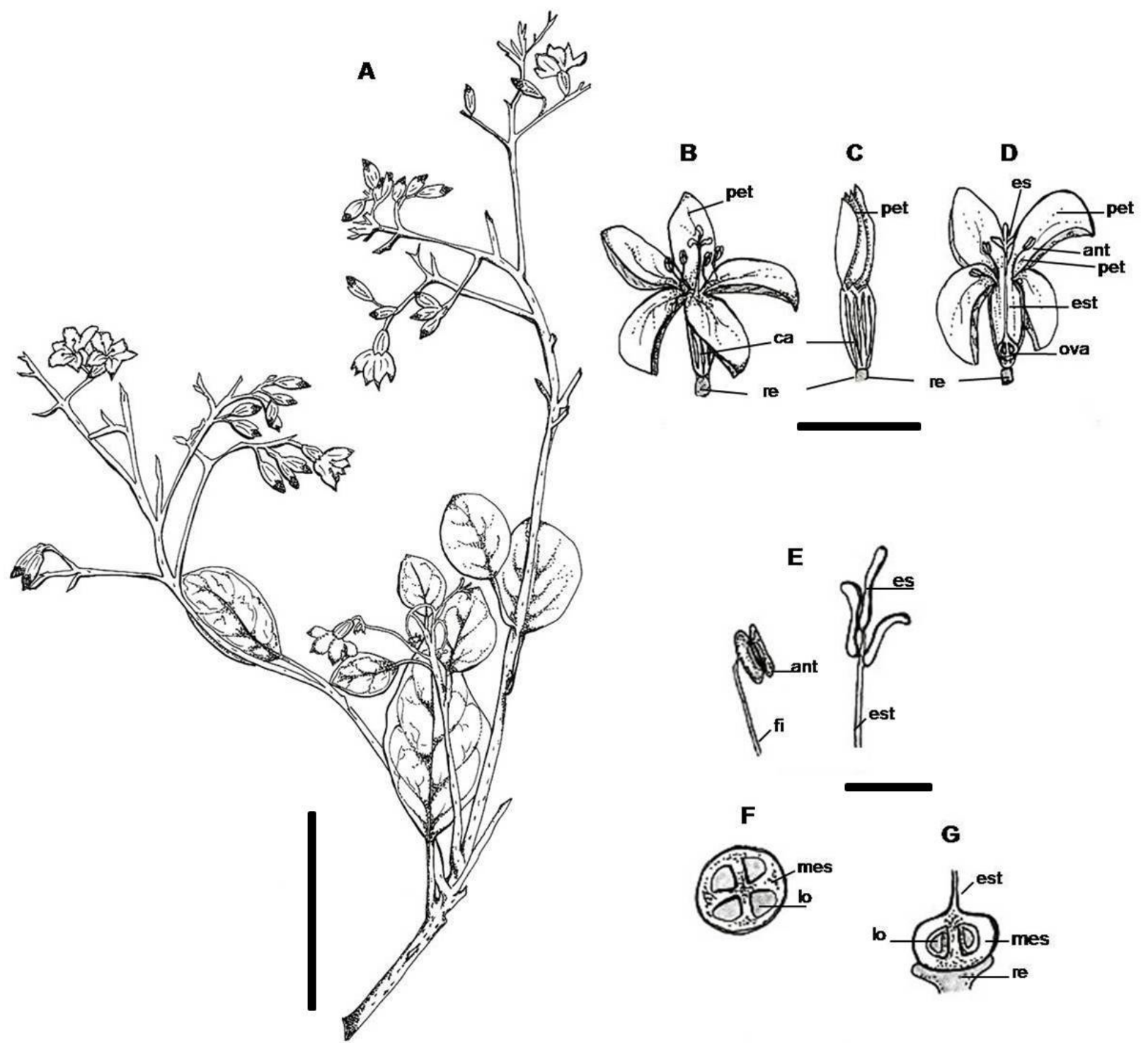

FIGURA 3: Ramo e flores de Cordia trichotoma. A - Ramo com inflorescência; B - Flor aberta; C - Botão floral; D - Flor/Corte transversal; E - Estame e Estigma; F - Ovário/Corte longitudinal; G Ovário/Corte transversal (ant - antera; ca - cálice; es - estigma; est - estilete; fi - filete; lo - lóculo; mes - mesocarpo; ova - ovário; pet - pétala; re - receptáculo). Barra de escala: $3 \mathrm{~cm}$ para Fig. A; $1 \mathrm{~cm}$ para B a D e $0.2 \mathrm{~cm}$ para as demais.

FIGURE 3: Branch and flowers of Cordia trichotoma. A - Branch with inflorescence; B - Flower open; C - Floral Button D - Flower / cross section; E - Stamen and Stigma; F - Ovary / Longitudinally, G - Ovary / Cross section (ant - anther; ca - cup ; es - stigma; est - estilet; fi - fillet; it - locule; mes - flesch; ova - Ovary; pet - petal; re - receptacle). Scale bar: $3 \mathrm{~cm}$ to Figure A, $1 \mathrm{~cm}$ for B to $\mathrm{D}$ and $0.2 \mathrm{~cm}$ for the others. 

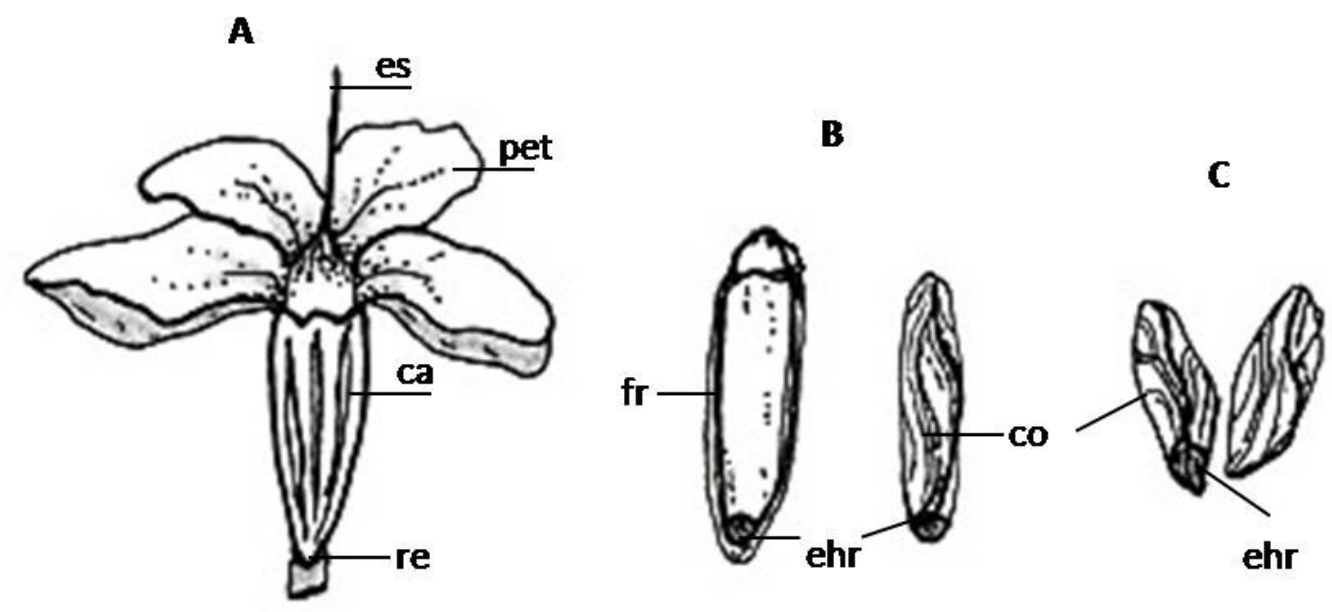

C

FIGURA 4: Fruto e semente de Cordia trichotoma. A - Fruto maduro; B - Fruto e semente; C - Semente/ Corte longitudinal (ca - cálice; co - cotilédones; ehr - eixo hipocótilo radicular; es - estigma; $\mathrm{fr}$ - fruto; pet - pétalas; re - receptáculo). Barra de escala $0,5 \mathrm{~cm}$.

FIGURE 4: The fruit and seed of Cordia trichotoma. A - Fruit mature B - Fruit and seed; C - Seed / slitting (ca - cup; co - cotyledons; ehr - hypocotyl root; es - stigma; fr - fruits; pet - petals; re - receptacle). Scale bar $0.5 \mathrm{~cm}$.

a $0,5 \mathrm{~cm}$ e 0,4 a $0,5 \mathrm{~cm}$, respectivamente. Essa variação, provavelmente, ocorre em função da variabilidade genética entre árvores matrizes e a influência ambiental durante o desenvolvimento reprodutivo. Assim, o tamanho de frutos e sementes pode variar entre plantas da mesma espécie, de ano para ano e, também, na mesma planta, como já relatado por Piña-Rodrigues e Aguiar (1993). Tais diferenças podem afetar o processo de regeneração da população (MORAES e ALVEZ, 2002), contudo a variação entre indivíduos, numa mesma população, possibilita a seleção com vistas à melhoria de um dado caractere (SANTOS et al., 2009).

O tamanho das sementes pode estar relacionado à quantidade de reserva, o que pode auxiliar o vigor das plântulas, concordando com Santos et al. (2009). Portanto, o tamanho e as características das sementes são de grande importância para o estudo de uma espécie, podendo auxiliar em testes germinativos e armazenamento de sementes e a distinção e classificação de lotes de sementes, por peso e tamanho, pode ser uma maneira eficiente de melhorar a qualidade em relação à uniformidade de emergência e vigor das plântulas (PEDRON et al., 2004).

Agerminação é do tipo epígea e as plântulas são fanerocotiledonares, com emergência curvada.
Os eventos do processo germinativo podem ser visualizados nas Figuras 5, onde, inicialmente, há reidratação da semente, a qual intumesce (Figura $5-\mathrm{A}$ ), emitindo a raiz primária (Figura $5-\mathrm{A}$; B), próxima ao hilo, entre o $6^{\circ}$ e $10^{\circ}$ dia após a semeadura.

A raiz primária é cilíndrica, desenvolve-se rapidamente, engrossando e sofrendo afinamento com dilatação na base (Figura 5 - B a E), sendo de coloração esbranquiçada. À medida que a raiz se alonga, aparecem pelos absorventes (Figura 5 C a F), de cor pérola. A coifa é glabra, cilíndrica, alongada e termina numa ponta aguda (Figura 5 B a F), de coloração amarela.

O colo é curto, cilíndrico, delimitado por um leve alargamento do hipocótilo, que também é cilíndrico, inicialmente curvo, tornando-se reto à medida que ocorre o seu alongamento (Figuras 32 - C; D e 33 - B a F). Nessa fase, o hipocótilo é herbáceo, de coloração verde-clara, elevando acima do solo os cotilédones (Figura $5-\mathrm{C}$; D) foliáceos, opostos, oblongos, com ápice obtuso a arredondado, base levemente truncada e bordos inteiros (Figura 5-F; G), inicialmente de coloração verde-clara, tornando-se mais escuros ao passar dos dias, visualizando-se entre estes o primeiro protófilo entre o $23^{\circ}$ e $30^{\circ}$ dia após a germinação (Figura $5 \mathrm{G}$ ). 


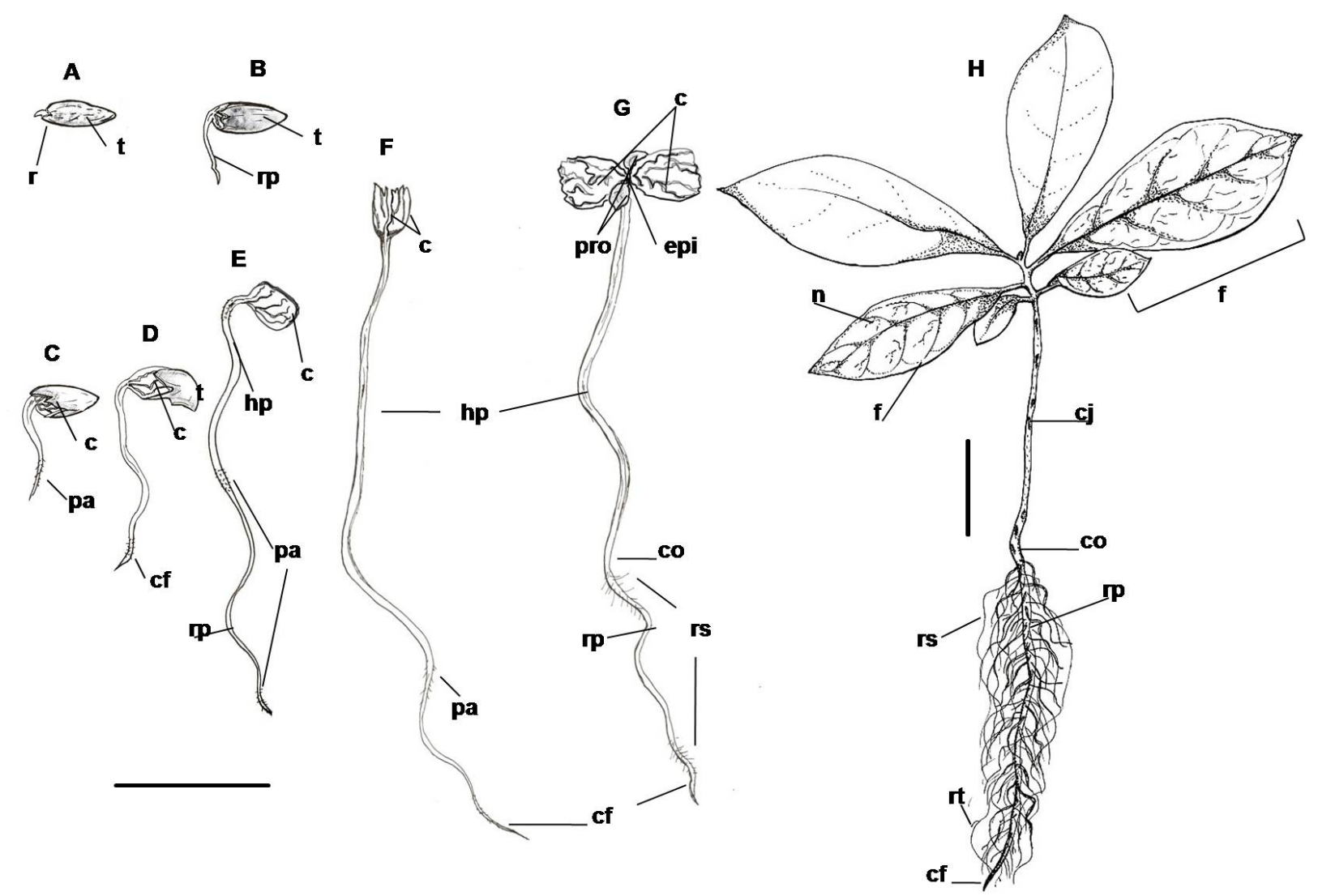

FIGURA 5: Estágios sucessivos de desenvolvimento inicial de Cordia trichotoma. A-Emissão da radícula; $\mathrm{B}$ a $\mathrm{F}$ - Alongamento da raiz primária e expansão dos cotilédones; $\mathrm{G}$ - Plântula (c - cotilédone; co - colo; cf - coifa; cj - caule jovem; epi - epicótilo; f - folha; hp - hipocótilo; $\mathrm{n}$ - nervuras; pa - pelos absorventes; pro - protófilo; $\mathrm{r}$ - radícula; $\mathrm{rp}$ - raiz primária; $\mathrm{rs}$ - raiz secundária; $\mathrm{rt}$ - raiz terciária; $\mathrm{t}$ - tegumento). Barra de escala: $2 \mathrm{~cm}$ Figuras A a $\mathrm{G} \mathrm{e} 4 \mathrm{~cm}$ para $\mathrm{H}$.

FIGURE 5: Successive stages of early development of Cordia trichotoma. A - Issue radicle; B F - Elongation of primary roots and expansion of cotyledons, G - Seedling (c - cotyledon; co - colon; cf hood; cj - young stem; epi - epicotyl f - leaf; hp - hypocotyl; $\mathrm{n}$ - ribs; pa - hairs; pro - foliage leaf; $\mathrm{r}$ - radicle; rp - primary root; $\mathrm{rs}$ - secondary root; $\mathrm{rt}$ - root tertiary, $\mathrm{t}$ - tegument). Scale bar: Figure $\mathrm{A} 2 \mathrm{~cm}$ to $4 \mathrm{~cm}$ for $\mathrm{G}$ and $\mathrm{H}$.

Com aproximadamente 25 dias de idade (Figura $5-\mathrm{G}$ ), a plântula está formada, com raiz pivotante de coloração verde-clara, de 10 a $15 \mathrm{~cm}$ de comprimento e raízes secundárias finas de coloração branco-amarelada. O hipocótilo é cilíndrico, estriado, glabro, de 6 a $8 \mathrm{~cm}$ de comprimento, coloração verdeamarelada na base e verde-clara no ápice. $\mathrm{O}$ epicótilo cilíndrico, de coloração verde-clara, mede em torno de 0,3 a $1 \mathrm{~cm}$ de comprimento e os protófilos são simples, opostos cruzados, peciolados, forma ovadoelíptica, de ápice e base arredondados a obtusos e bordos inteiros.

A muda, cinco meses após a germinação, possui altura média de $12 \mathrm{~cm}$ e diâmetro médio do colo de $4 \mathrm{~mm}$ (Figura $5-\mathrm{H}$ ). O sistema radicular é pivotante, raiz axial cilíndrica e sublenhosa, afinando gradualmente em direção à porção terminal, sendo a superfície glabra, de coloração amarelo-esverdeada. As raízes laterais são cilíndricas, sublenhosas, distribuídas em toda a extensão da raiz principal. Já o caule jovem é de consistência sub-herbácea, com superfície de coloração castanho-clara, levemente áspera, devido à existência de rachaduras desuniformes, longitudinais, tortuosas, curtas ou longas.

As folhas são simples, pecioladas, alternas, espiraladas, oblongo-agudas, subcoriáceas com base aguda, ápice acuminado (Figura $5-\mathrm{H}$ ), margem fracamente sinuada, ondulada e distintamente discolor, áspera e rica em pelos. Carvalho (2003) cita tais características quanto às folhas para a espécie na fase adulta. Por outro lado, quanto à descrição das 
etapas do processo germinativo, plântula e muda, não foram encontrados trabalhos científicos. Assim, tais informações servirão para a identificação da espécie nas fases iniciais de crescimento a campo.

\section{Análise de sementes}

Foram encontradas 24.591 sementes por quilograma com coeficiente de variação de $2,26 \%$, valor abaixo de $6 \%$, o qual é recomendado pela RAS (BRASIL, 2009), sendo que o resultado obtido neste trabalho demonstra que as sementes são uniformes, homogêneas e de tamanho semelhante.

Conforme Castiglioni (1975), um quilograma de frutos com cálice aderente, sem os pedúnculos e as pétalas, contém de 20.000 a 45.000 unidades. Rizzini (1976) citou 40.200, Kuniyoshi (1983) mencionou 37.347, semelhante a Lorenzi (2002) que descreveu a presença de 35.200 sementes por quilograma, enquanto Mendonça et al. (2001) observaram 56.100 unidades.

De acordo com Mendonça et al. (2001), essa variação pode ocorrer, principalmente, em função dos fatores climáticos, do solo, do local de produção e das alterações antrópicas na área onde os indivíduos arbóreos encontram-se estabelecidos.

A porcentagem de umidade em sementes da espécie foi de 51,16 \% com coeficiente de variação de $2,05 \%$. O elevado teor de água é característico de espécies recalcitrantes, de fato, Eibl et al. (1994) caracterizaram as sementes de louro sensíveis ao dessecamento. Esta característica pode comprometer o lote de sementes, caso este não sejam armazenado de forma adequada.

Dados referentes às características físicas e fisiológicas das sementes são de suma importância à produção de mudas (FERREIRA et al. 2001), já que o tamanho e a umidade podem estar relacionados ao vigor das mudas (GUI-FERREIRA e BORGHETTI, 2004).

A porcentagem de germinação alcançou índice de $40 \%$ e a de emergência, $29 \%$. Kuniyoshi (1983), coletando sementes de cinco árvores em Colombo, Paraná (PR), obteve germinação média de $11,6 \%$, com as taxas variando de 0 a $17,5 \%$. Mendonça et al. (2001), assim como Amaral et al. (1988), obtiveram $75 \%$ de germinação inicial.

As diferenças encontradas, comparandose os resultados, indicam variabilidade quanto à germinação, pressupondo que condições climáticas, de solo e genéticas podem influenciar a qualidade da semente, assim como o momento de máxima maturação fisiológica apropriada para coleta.

A avaliação do processo germinativo e de emergência em dias consecutivos permitiu a confecção das curvas (Figura 6). Observa-se que a germinação teve início entre o $18^{\circ}$ e $20^{\circ}$ dia após a semeadura, enquanto que a emergência, após o $24^{\circ}$ dia. O período do número máximo de sementes germinadas e emergidas foi aos 46 dias, sendo que, após este período, os índices se estabeleceram.

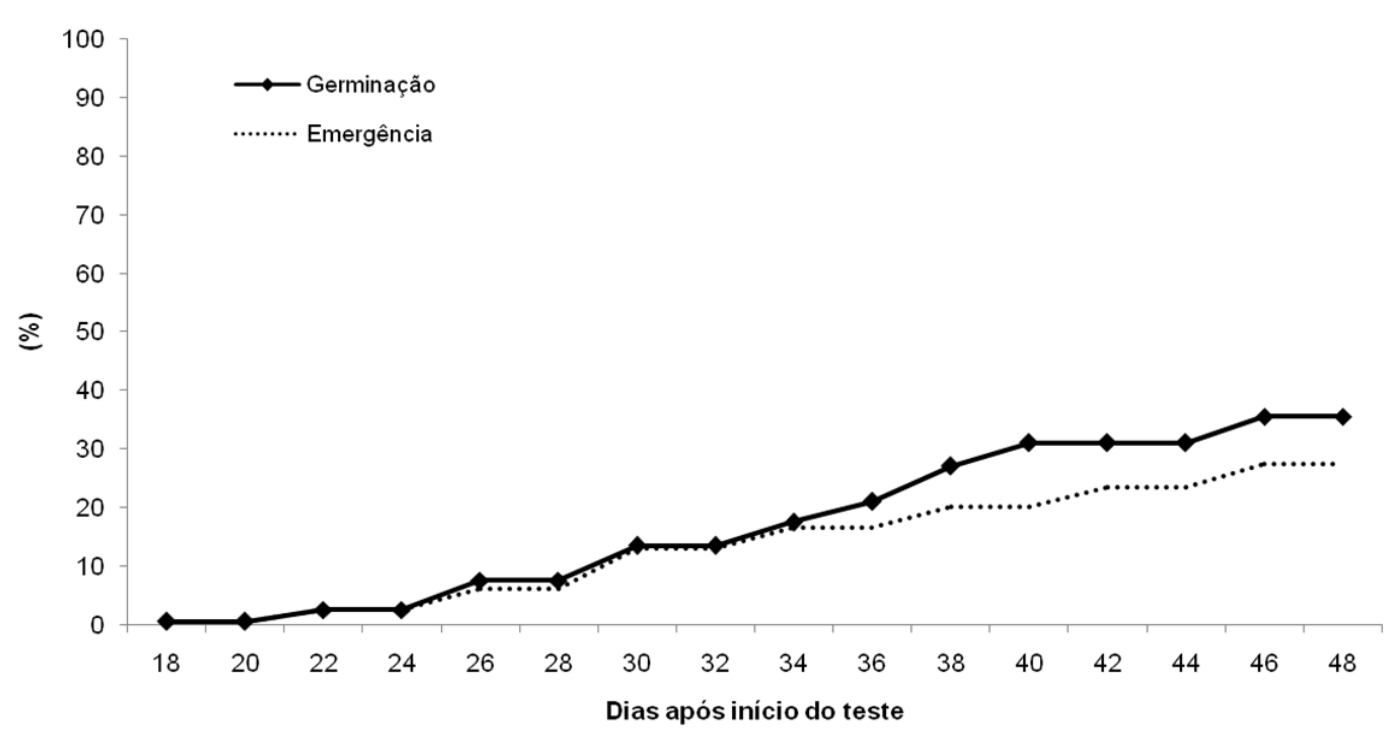

FIGURA 6: Germinação e emergência cumulativas de sementes de Cordia trichotoma, provenientes de um lote de sementes, Frederico Westphalen, RS, junho de 2008.

FIGURE 6: Cumulative germination and emergence of seeds of Cordia trichotoma, from a seed lot, Frederico Westphalen, Rio Grande do Sul state, June 2008. 
Ficou constatado valores de germinação semelhantes aos obtidos nos trabalhos mencionados na bibliografia, sendo os índices relativamente baixos, havendo a necessidade de estudos sobre condições ideais de germinação para esta espécie, observando-se o comportamento de sementes por árvore matriz, a fim de avaliar a influência do indivíduo na qualidade do lote de sementes.

\section{CONCLUSÕES}

Trabalhos envolvendo observações e coletas de flores de Cordia trichotoma podem ser realizados de fevereiro a junho, enquanto os estudos relativos a frutos e sementes deverão ser realizados de março a julho.

A espécie possui inflorescência cimosa paniculada, flores de coloração branca, hermafroditas; fruto simples, seco, indeiscente, drupáceo.

As sementes são cilíndricas, exalbuminosas, com embrião cotiledonar; germinação epígea e plântula fanerocotiledonar.

As sementes consideradas recalcitrantes apresentaram um número médio por quilograma de 24.591 unidades, umidade de $51 \%$, germinação de $40 \%$ e emergência de $29 \%$.

A muda, cinco meses após a germinação, possui altura média de $12 \mathrm{~cm}$ e diâmetro médio do colo de $4 \mathrm{~mm}$.

\section{REFERÊNCIAS BIBLIOGRÁFICAS}

AGAREZ, F. V.; RIZZINI, C. M.; PEREIRA, C. Botânica: taxonomia, morfologia e reprodução dos angiospermae: chaves para determinação das famílias. 2. ed. Rio de Janeiro: Âmbito Cultural, 1994. $256 \mathrm{p}$.

AGUIAR, F. F. A. et al. Influência do tamanho sobre a germinação de sementes de Caesalpinia echinata Lam. (Pau-Brasil). Revista Brasileira de Sementes, Pelotas, v. 18, n.2, p. 283-285, 1993.

AMARAL, D. M. I.; ALCALAY, N.; ANTONIO, M. G. Armazenamento de sementes de quatro espécies florestais do Rio Grande do Sul. In: CONGRESSO FLORESTAL ESTADUAL, 6., 1988, Nova Prata. Anais... Nova Prata: Prefeitura Municipal de Nova Prata/Meridional, 1988. p.373-397.

BARRoSO, G. M. et al. Frutos e Sementes: morfologia aplicada à sistemática de dicotiledôneas. Viçosa: Universidade Federal de Viçosa, 1999. $443 \mathrm{p}$.
BELL, A. D. Plant Form. An Illustrated Guide to Flowering Plant Morphology. New York; Tokyo: Oxford University Press, 1991. 341 p.

BOTELHO, S. A. et al. Aspectos morfológicos dos frutos, sementes, plântulas e mudas de Jatobá-docerrado (Hymenaea stigonocarpa Mart. ex Hayne) - Fabaceae. Revista Brasileira de Sementes, Pelotas, v. 22, n. 1, p. 144-152, 2000.

BRASIL. Ministério da Agricultura, Pecuária e Abastecimento. Secretaria de Defesa Agropecuária. Regras para análises de sementes. Brasília: Mapa/ ACS, 2009. 399 p.

CARVALHO, P. E. R. Espécies arbóreas brasileiras. Colombo: EMBRAPA/CNPR, Brasília: EMBRAPA-SPI, v.1, 2003. 1039 p.

CASTIGLIONI, J. A. Description botânica, florestal y tecnológica de las principales espécies indígenas de la Argentina. In: COZZO, D. (Ed.) Arboles forestales, maderas y silvicultura de La Argentina. Buenos Aires: Acme, 1975. p.38-60.

EIBL, B. I. et al. Ensayos de germinación y análisis cuantitativo en semillas de especies forestales nativas de Misiones, R.A. Yvyraretá, Eldorado, v. 5, n. 5, p. 33-48, 1994.

FERREIRA, R. A.; DAVIDE, A. C.; TONETTI, O. A. Morfologia de sementes e plântulas de pauterra (Qualea grandilfora - Vochysiaceae). Revista Brasileira de Sementes, Pelotas, v. 23, n. 1, p. 116122, 2001.

FOURNIER, L. A. Estudo preliminar sobre la floración em Roble de sabana, Tabebuia pentaphilla (L) Hemst. Revista Biologica Tropical, San José, v. 15, n. 2, p. 259-67, 1967.

FOURNIER, L. A. Un método cuantitativo para la medición de características fenológicas en árboles. Turrialba, San José, v. 24, n. 4, p. 422-423, 1974. GANDERS, F. R. The biology of heterostyly. New Zealend Journal of Botany, v. 17, p. 607-635. 1979.

GONÇALVES, E. G.; LORENZI, H. Morfologia Vegetal: Organografia e Dicionário Ilustrado de Morfologia das Plantas Vasculares. São Paulo: Instituto Plantarum de Estudos da Flora, 2007. $416 \mathrm{p}$.

GUI-FERREIRA, A.; BORGHETTI, F. Germinação: do básico ao aplicado. Porto Alegre: Artmed, 2004. 323 p.

JUDD, W. S.; CAMPBELL, C. S.; KELLOGG, E. A. Plant Systematics, Massachusetts: Sinauer Associates, 1999. 464 p.

KUNIYOSHI, Y. S. Morfologia da semente e da germinação de 25 espécies arbóreas de 
uma floresta com araucária. 1983. Dissertação (Mestrado em Ciências Florestais)-Universidade Federal do Paraná, Curitiba, 1983.

LORENZI, H. Árvores Brasileiras: Manual de identificação e cultivo de plantas arbóreas nativas do Brasil. 4. ed. Novassa Odessa: Plantarum, 2002, 368 p. v. 1.

MENDONÇA, E. A. F.; RAMOS, N. P.; PAULA, R. C. Viabilidade de sementes de Cordia trichotoma (Vellozo) Arrabida ex Steudel (Louro-pardo) pelo teste de tetrazólio. Revista Brasileira de Sementes, Pelotas, v. 23, n. 2, p. 64-71. 2001.

MORAES, P. L. R. de.; ALVEZ, M. C. Biometria de frutos e diásporos de Cryptocarya aschersoniana Mez e Cryptocarya moschata Nees (Lauraceae). Biota Neotropica, Campinas, v. 2, n. 1, p. 1-11, 2002

MORELLATO, L. P. C. et al. Estudo comparativo da fenologia de espécies arbóreas de floresta de altitude e floresta mesófila semi-decidua na Serra do Japi, Jundiaí, São Paulo. Revista Brasileira de Botânica, São Paulo, v. 12, p. 85-98, 1989.

MOURÃO, K. S. M. et al. Morfo-anatomia da plântula e do tirodendro de Trichilia catigua A. Juss., T. elegans A. Juss. e T. pallida Sw. (Meliaceae). Acta Scientiarum, Maringá, v. 24, n. 2, p. 601-610, 2002.

NEWSTROM, L. E.; FRANKIE, G. W.; BAKER, H. G. A new classification for plant phenology based on flowering patterns in lowland tropical rain forest trees at La Selva, Costa Rica. Biotrópica, St. Louis, v. 26, p. 141-159, 1994.

PEDRON, F. A.; MENEZES, J. P.; MENEZES, N. L. Parâmetros biométricos de fruto, endocarpo e semente de butiazeiro. Ciência Rural, Santa Maria, v. 34, n. 2, p. $585-586,2004$.

PIÑA-RODRIGUES, F. C. M. Guia prático para a colheita e manejo de sementes florestais tropicais. Rio de Janeiro: Idaco, 2002. 40 p.

PIÑA-RODRIGUES, F. C. M.; FREIRE, J. M.; SILVA, L. D. Parâmetros genéticos para colheita de sementes de espécies florestais. In: PIÑARODRIGUES, F. C. M. ... et al. (Ed.). Parâmetros técnicos para produção de sementes florestais. Seropédica: Rioesba - Rede Mata Atlântica de Sementes Florestais, 2007, p.51-102.

REITZ, R.; KLEIN, R. M.; REIS, A. Projeto Madeira do Rio Grande do Sul. Porto Alegre: SUDESUL, 1988. $525 \mathrm{p}$.

RIZZINI, C. T. Tratado da Fitogeografia do Brasil: Aspectos ecológicos, sociológicos e florísticos. 2. ed. Rio de Janeiro: Âmbito Cultural, 1976. 747 p.

SANTOS, F. S dos. et al. Biometria e qualidade fisiológica de sementes de diferentes matrizes de Tabebuia chrysotricha (Mart. Ex A. DC.) Standl. Scientia Foresetalis, Piracicaba, v. 37, n. 82, p. 163-173, jun. 2009.

SEMA/UFSM-RS. Governo do Estado. Secretaria Estadual do Meio Ambiente. Relatório Final do Inventário Florestal Contínuo do Rio Grande do Sul. Porto Alegre, 2001. 706p. v.1, 2.

SMITH, L. B. Boragináceas. In: REITZ, R. (Ed.) Flora Ilustrada Catarinense, Itajaí: Herbário Barbosa Rodrigues, 1970. p. 1-85.

SOUZA, A. L. de. Morphology and Anatomy of the Cordia trichotoma (Vell.) Arrab. ex I. M. Johnst diaspore (BORAGINACEAE). Brazialian Archives of Biology and Technology, Curitiba, v. 51, n. 4, p. 761-768. July/Aug. 2008.

SOUZA, L. A. de. Morfologia e anatomia vegetal: célula, tecidos, órgãos e plântula. Ponta Grossa: UEPG, 2003. 259 p.

SPINA, A. P. et al. Floração, frutificação e síndromes de dispersão de uma comunidade de floresta de brejo na região de Campinas (SP). Acta Botanica Brasílica, São Paulo, v. 15, n. 3, p. 349-368, 2001.

TARODA, N.; GIBBS, P. Studies on the genus Cordis L. (Boraginaceae) in Brazil a new infrageneric classification and conspectus. Revista Brasileira de Botânica, São Paulo, v. 9, p. 1-6, 1986.

VIDAL, W. N.; VIDAL M. R. R. Botânica Organografia; Quadros Sinóticos Ilustrados de Fanerógamos. 4. ed. Viçosa: UFV, 2000. 124 p.

WEBERLING, F. Morphology of flowers and inflorescences. Cambridge: University Press, 1989. $405 \mathrm{p}$. 